IMAGES IN CLINICAL PRACTICE

\title{
SERPENTINE SKIN LESION ON FOOT WITH INTENSE ITCHING
}

\author{
Nuno Oliveira ${ }^{1}$, Rita Lacerda Vidal², Sónia Regina Silva ${ }^{1}$. \\ ${ }^{1}$ Department of Pediatrics, Centro Hospitalar do Baixo Vouga, Aveiro, Portugal, \\ ${ }^{2}$ Department of Pediatrics, Centro Hospitalar Entre Douro e Vouga, Aveiro, Portugal.
}

\section{KEYWORDS}

Cutaneous larva migrans, dermatosis, Ancylostoma

A 2-year-old boy presented with a linear wandering erythematous lesion on the right foot for 2 days. The lesion had been rapidly increasing in size forming a serpiginous tract with erythema and was intensely pruritic. Examination revealed a slightly raised erythematous serpentine lesion and local edema on the right foot (Figure 1). During the examination, the patient's mother informed us of their recent trip to Brazil, where they visited a beach that had stray dogs, and from which they had returned the day before. The patient was treated with $400 \mathrm{mg}$ of oral albendazole once a day for 5 days and due to severe pruritus also received oral desloratadine $1.25 \mathrm{mg}$ once a day. The lesion totally disappeared with treatment.

\section{What is the diagnosis?}

Cutaneous larva migrans (CLM). It is a self-limited dermatosis caused by the infection and migration of an animal hookworm larvae in patient's epidermis. The most common parasites that cause CLM are Ancylostoma caninum and Ancylostoma braziliense, who have dogs and cats as their hosts. ${ }^{1}$ CLM is characterized by serpiginous or linear raised erythematous tracks, intensely pruritic that occur on unprotected skin (typically involving the feet) that has come into contact with sandy, moist soil contaminated by dog or cat feces containing hookworm eggs, with conditions for infection being more favorable in tropical or subtropical climates. ${ }^{2}$ In most cases, the diagnosis of CLM is based on the typical skin findings and the previous travel history with a real possibility of exposure as was seen in our patient. ${ }^{3}$ Complications include impetigo and local or general allergic reactions. Although the disease might be self-limited, spontaneous cure takes several weeks or months. The potential complications, together with the intense pruritus and the duration of the disease, justifies the treatment. Treatment options include oral albendazole (for children with more than 2 years old: $400 \mathrm{mg}$ once a day for 3 to 7 days) or oral ivermectin (for children more than $15 \mathrm{~kg}: 200 \mathrm{mcg} / \mathrm{kg}$ as a single dose). ${ }^{4}$ Because tourists are usually infected by walking or lying on tropical sandy beaches contaminated by dog feces, the best way to prevent CLM is to ban dogs from beaches or wear suitable footwear when walking

Address for Correspondence: Nuno Oliveira, Pediatric Department, Centro Hospitalar do Baixo Vouga, Aveiro, Portugal.

Email: nunofp.oliveira@gmail.com

(C)2021 Pediatric Oncall

\section{ARTICLE HISTORY}

Received 28 June 2020

Accepted 14 August 2020

Figure 1. Local edema with raised erythematous serpentine lesion on the right foot.

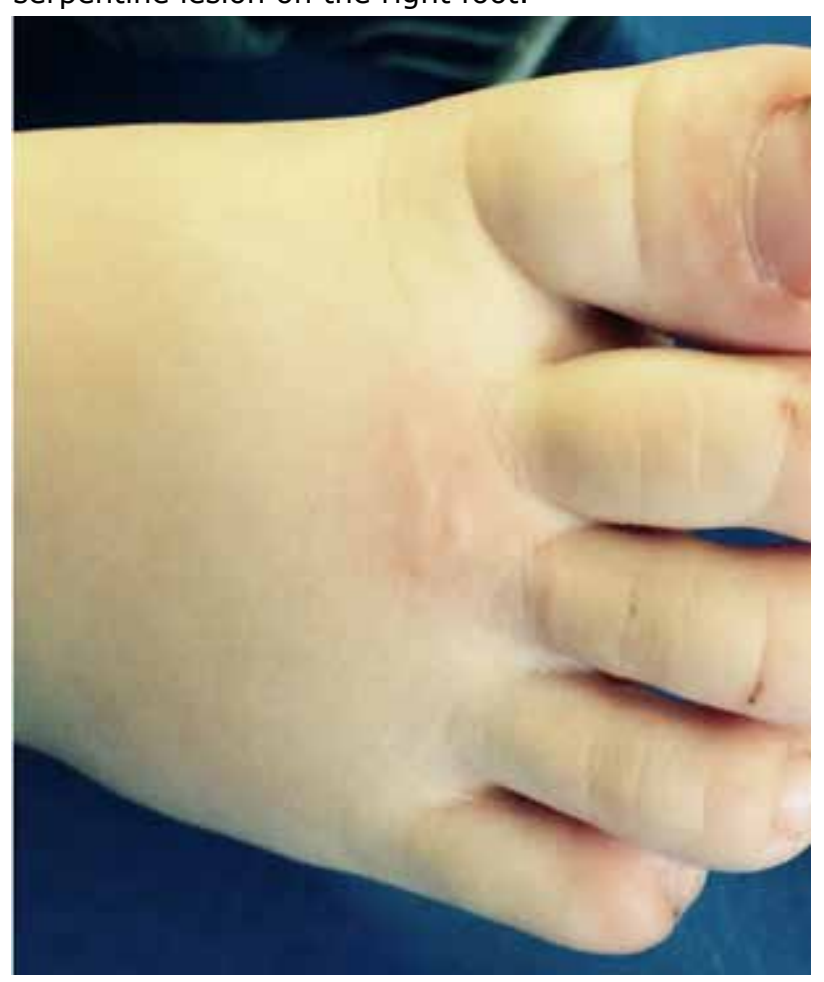

in sandy areas. ${ }^{2}$

\section{Compliance with Ethical Standards}

Funding None

Conflict of Interest None

\section{References:}

1. Le Joncour A, Lacour SA, Lecso G, Regnier S, Guillot J, Caumes E. Molecular characterization of Ancylostoma braziliense larvae in a patient with hookworm-related cutaneous larva migrans. Am J Trop Med Hyg. 2012;86:843

2. Heukelbach J, Feldmeier H. Epidemiological and clinical characteristics of hookworm related cutaneous larva migrans. Lancet Infect Dis. 2008;8:302-309.

3. Leung AKC, Barankin B, Hon KLE. Cutaneous Larva Migrans. Recent Pat Inflamm Allergy Drug Discov. 2017;11:2-11

4. American Academy of Pediatrics. [Chapter title.] In: Kimberlin DW, Brady MT, Jackson MA, Long SS, eds. Red Book: 2015 Report of the Committee on Infectious Diseases. 30th ed. Elk Grove Village, IL: American Academy of Pediatrics; 2015:315-316;932 